\title{
Cartas à Dona Suzana: uma viagem de São Paulo a Salvador na formação de educadores científicos com Paulo Freire
}

\section{Letters to Mrs. Suzana: a trip from São Paulo to Salvador in the training of scientific educators with Paulo Freire}

\author{
Rafael Vitame Kauano ${ }^{1}$ \\ Felipe Barbosa Dias ${ }^{2}$ \\ André Kyoshi Fujii Ferrazo 3 \\ Paula de Oliveira Souza 4
}

\begin{abstract}
Resumo
O presente trabalho tem como objetivo apresentar o relato de uma atividade didática desenvolvida com estudantes das licenciaturas em Ciências Biológicas e Pedagogia no ano de 2021 e analisar a potencialidade do uso de um documentário para a formação inicial de educadores científicos. Esta atividade foi realizada online no contexto do ensino remoto emergencial e teve como inspiração princípios da Investigação Temática e da Abordagem Temática Freireana para a sensibilização à existência de Universos Temáticos Significativos (UTS). Foi utilizado como recurso a série documental "Street Food América Latina" enquanto uma proposta de simulação de determinada realidade. Como produto final da atividade, e material de análise deste relato, cartas destinadas à Dona Suzana, protagonista do documentário, foram produzidas cartas pelas pessoas licenciandas onde puderam, em um exercício de dialogicidade, mobilizar alguns aspectos da pedagogia problematizadora de Paulo Freire a partir das relações temáticas significativas que emergiram das discussões dos grupos. Assim como indica Freire, escolhemos um "modo de caminhar" para este exercício diante das limitações impostas pela pandemia. Notamos que para além da percepção de um UTS, há incorporação de elementos presentes nas categorias de Paulo Freire na composição das cartas, sendo que a problematização, dialogicidade, síntese cultural e práxis foram elementos marcantes.
\end{abstract}

Palavras-chave: Abordagem Temática Freireana. Investigação Temática. Educação Científica. Documentário.

\begin{abstract}
This paper aims to present the report of a didactic activity developed with undergraduate students in Biological Sciences and Pedagogy during 2021 and to analyze the potential of using a documentary for the initial training of science educators. This activity was carried

\footnotetext{
1 Faculdade de Educação - USP, Embraza Ciência, E-mail: rafa.kawanobio@gmail.com, https://orcid.org/0000-0003-2383-3120

2 Faculdade de Educação - USP, E-mail: felipedias.bio@usp.br, https://orcid.org/0000-0002-5870-3644

3 Faculdade de Educação - USP, E-mail: andre.k.ferrazo@gmail.com, https://orcid.org/0000-0003-3085-3613

${ }^{4}$ Faculdade de Educação - USP, E-mail: paaulasouzza@gmail.com, https://orcid.org/0000-0003-2630-6457
} 


\section{-Revista de Iniciação à Docência, v.6, n.2, 2021- \\ Publicação: dezembro, 2021 - ISSN 2525-4332}

out online in the context of emergency remote teaching and was inspired by the principles of Thematic Research and the Freirean Thematic Approach to raise awareness of the existence of Significant Thematic Universes (STU). The series "Street Food Latin America" was used as a resource to simulate a reality case. As a final product of the activity, and material for the analysis of this report, letters to Dona Suzana, protagonist of the documentary, were produced by the graduates where they were able, in an exercise of dialogicity, to mobilize some aspects of Paulo Freire's problematizing pedagogy from relations significant themes that emerged from the group discussions. As Freire indicates, we chose a "way of walking" for this exercise given the limitations imposed by the pandemic. We note that, in addition to the perception of a STU, there is an incorporation of elements present in Paulo Freire's categories in the composition of the letters, and the problematization, dialogicity, cultural synthesis and praxis were striking elements.

Keywords: Freirean Thematic Approach. Thematic Research. Scientific Education. Documentary.

Para Dona Suzana.

\section{Introdução}

O presente artigo apresenta o relato e a análise de uma atividade chamada "Cartas para Dona Suzana", elaborada pelas equipes das disciplinas de Metodologia do Ensino de Ciências para a Pedagogia e Metodologia do Ensino de Ciências Biológicas I, ambas oferecidas pela Faculdade de Educação da Universidade de São Paulo. Esta atividade foi desenvolvida com as pessoas licenciandas dos dois cursos dentro do contexto do ensino remoto emergencial, ainda no primeiro semestre de 2021, e teve como principal objetivo criar um ambiente de exercício de aspectos da Investigação Temática (IT) proposta por Paulo Freire (2018) no contexto do ensino de ciências da natureza. Ao mesmo tempo, reconhecemos algumas limitações da referida atividade diante da proposta original da IT. Tanto a atividade, quanto às suas limitações, serão discorridas ao longo do texto.

Ambas as disciplinas são estruturadas a partir da conexão de aspectos do pensamento de Paulo Freire e perspectivas de educação científica, fundamentadas na articulação entre Ciência, Tecnologia, Sociedade e Ambiente (CTSA) e em perspectiva da Alfabetização Científica Ampliada (ACA). Auler e Delizoicov (2001) apresentam duas perspectivas para Alfabetização Científica e Tecnológica (ACT): reducionista e ampliada. A perspectiva reducionista compromete-se com a transmissão antidialógica e bancária dos conteúdos científicos. Em contrapartida, ACT ampliada pode ser considerada uma educação em ciências de caráter progressista, direcionada a partir de uma proposta de superação de mitos referentes à Ciência e Tecnologia: modelos de decisões tecnocráticas, salvacionismo científico e tecnológico e o determinismo tecnológico. 


\section{-Revista de Iniciação à Docência, v.6, n.2, 2021- \\ Publicação: dezembro, 2021 - ISSN 2525-4332}

Dada esta informação, os componentes curriculares das disciplinas têm como objetivo trabalhar durante a formação de educadores em ciências - aqui e nas disciplinas considerados como professores, educadores da educação não formal e popular, bem como a formação de divulgadores científicos - elementos de contextualização e construção de problematizações a partir de uma perspectiva temática. Portanto, defendemos uma perspectiva de educação em ciências ancorada em autores que articulam com as ideias de Paulo Freire (DELIZOICOV, 1983; PERNAMBUCO, 1981, 1993, 1994; AULER; DELIZOICOV, 2015; SILVA, 2004, 2007; MUENCHEN; AULER, 2007; MUENCHEN, 2010; GEHLEN, 2009; GEHLEN et al., 2014), que busca promover uma formação crítica e problematizadora de uma realidade pautada também pelas relações entre ciência e tecnologia (AULER, 2003).

Destacamos que a visão incorporada nessas práticas é a de uma ciência e tecnologia não neutras, sendo assim, entendemos o fazer científico e a produção tecnológica como atividades permeadas pelas relações e contradições sociais e disputas de poder. Essa visão permite a promoção de uma ACA que se orienta na direção da problematização e superação dos mitos referentes à CT (AULER; DELIZOICOV, 2001) e da promoção de uma cultura de participação social em processos de $\mathrm{CT}$, sendo este, um objetivo importante da educação em ciências que vem sendo debatido por autores que articulam pressupostos presentes nas obras de Freire (SANTOS; AULER, 2019; ROSA; STRIEDER, 2021).

Delizoicov (1982) pode ser considerado um dos primeiros autores a articular o ensino de ciências na educação formal e as ideias de Paulo Freire. Em seus trabalhos, o autor propõe a IT como forma de obter, por meio da ação dialógica, os temas referentes ao ensino de ciências que permeiam o contexto das contradições vividas pelos educandos. Neste mesmo caminho, Martha Pernambuco (1993), outra expoente da inserção de Paulo Freire na educação em ciências, reforça o diálogo como forma de pessoas educandas e educadoras construírem conhecimentos juntos e assim explorar novas formas de ver o mundo. O diálogo deve partir do universo dos educandos, dos conhecimentos prévios que carregam com seus respectivos significados e relevância histórica, social e cultural. Partir da realidade desses sujeitos, é compreendê-los, não como um vaso vazio a ser preenchido, mas enquanto pessoas em construção no e com o mundo, hábeis a modificá-lo e dignos de respeito (PERNAMBUCO, 1993).

Nessa perspectiva, a educação em ciências se torna um ato de promoção da tomada de consciência, como aponta Angotti (2001). Em referência a Freire (2018), Angotti (2001) também defende uma construção do currículo de ciências por meio de temáticas como processo de desfragmentação do ensino de ciências que ainda tem um caráter fortemente conteudista e seccionado. Esse movimento de incorporação da IT e busca por Temas Geradores (FREIRE, 2018), proposto inicialmente pelos autores e autora supracitados, concretizou-se na elaboração metodológica da Abordagem Temática Freireana (ATF) para obtenção de temas a serem trabalhados curricularmente; e a 
construção dos "Três Momentos Pedagógicos" enquanto método para o trabalho em ambientes educativos destes temas (DELIZOICOV et al., 2018).

Destacamos a relação da ATF com o ensino de ciências, especialmente na formação de professores e educadores - nosso objeto de discussão. Tais pressupostos teórico-metodológicos apresentados são utilizados no ensino de ciências a fim de elaborar propostas que almejam reconfigurar o currículo. A ATF (SOUSA et al., 2014; DELIZOICOV et al., 2018; DEMERTINI; SILVA, 2021) e a "Práxis Curricular via Tema Gerador" (SILVA, 2004) são exemplos do emprego desses pressupostos que buscam selecionar conteúdos e conceitos científicos a partir dos temas geradores. De acordo com Centa e Muenchen (2018), o exercício teórico-prático da IT vem sendo implementado em diversos contextos no ensino de ciências desde a década de 1980, tanto na formação de discentes, quanto na de docentes. Ao mesmo tempo, Torres (2010) comenta que as iniciativas de utilização dessa dinâmica na formação de professores ainda são incipientes. Neste trabalho, assumimos uma ação educativa como uma dessas iniciativas em um contexto de formação inicial de educadores no ensino remoto.

Assim, dados os pressupostos da construção do contexto formativo aqui apresentado, relatamos neste trabalho uma experiência de utilização de documentários na formação inicial de pessoas educadoras como uma possibilidade para o exercício de percepção de realidades complexas e específicas. Logo, levantamos a seguinte pergunta: "Documentários que relatam e exploram determinadas realidades poderiam mediar e auxiliar pessoas educadoras em formação inicial a começar a desenvolver olhares atentos para a percepção de contradições e alguns aspectos estruturantes de contextos de vida que são fundamentais à IT?".

Partindo desta pergunta, levantamos como os objetivos deste trabalho: i) relatar a experiência de aplicação de uma atividade com objetivo de sensibilização para construção de outros olhares a universos temáticos significativos; e ii) analisar a potencialidade do uso do documentário Street Food América Latina, de viés sociocultural, no contexto da formação de pessoas professoras e educadoras de ciências e biologia a partir de teorizações gerais sobre IT e ATF e de categorias freireanas centrais: problematização, dialogicidade, síntese cultural e práxis.

\section{Documentários, educação em ciências e o Street Food América Latina}

Reservamos o segundo item deste artigo para que, de forma breve, possamos contextualizar o uso de documentários na formação inicial de pessoas educadoras. Geralmente quando pensamos na relação entre cinematografia, ciência e tecnologia, nosso imaginário comum é transportado em um primeiro momento para o gênero de ficção científica. Barbosa e Bazzo (2013) nos listam uma série de obras cinematográficas 
-Revista de Iniciação à Docência, v.6, n.2, 2021-

Publicação: dezembro, 2021 - ISSN 2525-4332

que marcam a ficção científica como gênero que traz em si um tipo de predição do futuro da humanidade: 2001 - uma odisseia no espaço, De volta para o futuro, Eu robô, Avatar, entre outros.

No contexto do ensino de ciências, Bazzo e Barboza (2013) apontam que documentários são ferramentas didáticas relevantes porque podem fomentar alterações de concepções deturpadas sobre a ciência e tecnologia e evidenciar a não neutralidade na relação existente entre ciência, tecnologia e sociedade. Desse modo, podem promover a discussão sobre assuntos sociopolíticos e avançar na democratização do debate científico. O documentário é uma produção cinematográfica que historicamente surgiu para se opor à ficção e retratar o mundo real (TORRES, 2011). Jesus (2008) afirma que a origem deste gênero está atrelada à educação, uma vez que o documentário teria um papel de reforçar a educação formal que não conseguia abranger a realidade concreta do mundo.

Nichols (2005) classifica o gênero documentário em seis subgêneros: expositivo, poético, participativo, observacional, reflexivo e performativo. Segundo o autor, a classificação está relacionada com a evolução das produções ao longo do tempo; assim, os subgêneros não são excludentes entre si, ocorrendo muitas vezes sobreposições, diálogos entre eles e até predominância de características de um sobre o outro. Partindo das características do subgênero participativo, apontadas por Nichols (2005), onde existe a intenção de mostrar a presença do documentarista e sua equipe e a interação entre eles com os atores sociais retratados no documentário, buscando mostrar como é a imersão nesse mundo no qual se retrata, o documentário Street Food explora a tradição e a história de diferentes pessoas e a com comida de rua, realiza uma imersão na vida das pessoas retratadas ao longo dos episódios, a fim de mostrar o seu modo de vida, dia a dia e histórias.

Justamente por isso, a escolha da série documental Street Food América Latina episódio de Salvador, Brasil foi feita considerando a grande riqueza cultural apresentada nesta obra que amplifica elementos de vozes humanas estruturantes de uma dada realidade. A partir destes elementos culturais que orbitam em torno de um tema central que é alimentação enquanto um marcador de cotidianidade e territorialidade, a obra relata o cotidiano de personagens reais habitantes da cidade de Salvador - Bahia; entre elas está Dona Suzana, protagonista do episódio e dona de um famoso restaurante local chamado Ré Restaurante.

Apesar de não ser uma produção que tenha como objetivo tratar questões de ciência, tecnologia e suas conexões com a sociedade, as pessoas responsáveis pelas disciplinas identificaram em seus episódios elementos que podem ser trabalhados sob o olhar das ciências naturais e suas interconexões com outros conhecimentos. Podemos citar exemplos: a alimentação e ganho energético, a biodiversidade, as conexões com o ambiente, entre outros aspectos que podem ser discutidos com olhar cuidadoso como a 
transformação da matéria e, até mesmo, a introdução de espécies exóticas ao longo da história de colonização, escravização e formação do Brasil dentro da perspectiva colonizadora.

Ao mesmo tempo que o episódio escolhido se atém a falar sobre pratos típicos da Bahia, ele expõe contextos locais e propicia que a voz de distintas realidades, em sua maioria periféricas, sejam protagonizadas. Portanto, assumimos a experiência de trazê-lo como fonte de um exercício de IT em uma atividade remota de formação inicial de professores nas licenciaturas de pedagogia e ciências biológicas.

\section{Investigação Temática e o relato da atividade}

Os estudos do pesquisador e educador popular brasileiro Paulo Freire podem ser considerados um marco na história da educação no Brasil e em todo o mundo. Dentre as suas contribuições, a metodologia da IT se constituiu como uma das ferramentas mais importantes para o campo da educação problematizadora. De acordo com Freire (2018), a IT pode ser utilizada para pesquisar o Universo Temático Significativo (UTS) de uma dada realidade e contribui para que os temas geradores possam emergir durante esse processo. É em um movimento dialógico problematizador que a IT objetiva desvelar os temas geradores imbricados nas situações-limite vivenciadas pelos sujeitos e entendidas por eles como uma situação existencial para a qual não há escolhas, senão, adaptar-se à realidade imposta (FREIRE, 2018). Nas palavras de Freire:

[...] a investigação temática não se pode reduzir a um ato puramente mecânico, uma vez que é processo de busca, de conhecimento, de criação. Daí que seja necessário que os sujeitos investigadores vão descobrindo a interpretação dos problemas no encadeamento dos temas significativos. $O$ objetivo fundamental da investigação é captar como os indivíduos pensam sua realidade e o que pensam sobre ela, não para fazer com que sejam "consumidores" de "cultura", mas para que sejam criadores de cultura. Daí que a investigação do pensar seja um ato de criação cultural e não de consumo. E por ser um ato de criação, como devem ser os atos humanos, não pode deixar de ser comunicativo, dialógico e participante (FREIRE, 2014, p. 103-106).

É na construção coletiva de uma comunicação dialógica, problematizadora e participativa, considerando as situações-limite, que a IT pode se estabelecer em contextos educacionais. Freire (2018) propõe que essa metodologia seja entendida como um "modo de caminhar" e não apenas como regras e técnicas a serem seguidas a fim de alcançar um resultado esperado. Decerto, o autor indica algumas etapas metodológicas importantes, tais como: i) o levantamento preliminar; ii) as codificações, sendo estas representadas pelas situações existenciais e significativas mediadas pelo mundo o qual os sujeitos estão inseridos; iii) os diálogos descodificadores, responsáveis pela tradução dialético-crítica da situação codificada e protagonizado coletivamente pelas pessoas 


\section{-Revista de Iniciação à Docência, v.6, n.2, 2021- \\ Publicação: dezembro, 2021 - ISSN 2525-4332}

educandas; e iv) a redução temática, cuja proposta visa construir um programa educativo, referenciado nos temas geradores, por especialistas de diferentes áreas (FREIRE, 2018).

Sobre este alicerce, propomos um exercício de sensibilização para o UTS por meio da atividade "Cartas para Dona Suzana", que possui como suporte audiovisual o documentário Street Food América Latina - episódio de Salvador. As etapas desta atividade - realizada em uma única aula síncrona com duração de três horas - se deram durante e após a exibição do episódio. Durante a exibição, os estudantes tiveram que observar atentamente a realidade local de Dona Suzana, protagonista do episódio, e registrar contradições, os elementos ou temáticas do cotidiano da personagem que pudessem ser relacionados as questões das ciências naturais e tecnologia.

Após a exibição, as pessoas licenciandas se reuniram em grupos para discutir suas respectivas observações e registros. Como produto final da atividade, material de análise deste relato, cada grupo produziu uma carta destinada à Dona Suzana, onde puderam, em um exercício de dialogicidade, mobilizar alguns aspectos da pedagogia problematizadora de Paulo Freire a partir das relações temáticas e conceituais significativas - o UTS - que emergiram das discussões de cada grupo.

"Cartas para Dona Suzana" foi realizada como uma proposta de exercício de IT, por meio de aspectos da ATF desenvolvida por Delizoicov et al. (2018). Segundo os autores, existem cinco etapas na ATF: i) levantamento preliminar da realidade local; ii) análise das situações e escolha das codificações; iii) diálogos descodificadores; iv) redução temática; e v) sala de aula. Faz-se necessário esclarecer que essa proposta se deu nas aulas iniciais de ambas as disciplinas nas quais o objetivo era estimular olhares atentos para a realidade e não, neste caso, à construção de um programa curricular. Assim, em direção a um "modo de caminhar" pedagógico com a utilização do documentário, a produção das cartas pelos grupos de alunos pode ser aproximada à última etapa da ATF, ou seja, uma situação pedagógica. No entanto, durante o processo de análise, coube a nós fazer os seguintes questionamentos: as outras etapas apareceram durante a realização da atividade? Se sim, de que forma?

De acordo com Nascimento e Linsingen (2006), o levantamento preliminar das condições locais, juntamente com a escolha das suas respectivas contradições - primeira e segunda etapa -, podem ser realizados por meio de observações da área e de suas diferentes atividades cotidianas, bem como ter as suas contradições escolhidas pela equipe de investigadores/educadores para a elaboração das codificações. Já os diálogos descodificadores e a redução temática - terceira e quarta etapa - são momentos importantes que carecem, respectivamente, de problematizações em conjunto e de uma interdisciplinaridade na identificação/seleção dos temas geradores e demais conteúdos (NASCIMENTO; LINSINGEN, 2006).

Durante o desenvolvimento da atividade pudemos observar quais aspectos das etapas gerais da ATF se fizeram presentes (Tabela 1), mesmo que alguns mais efêmeros 


\section{-Revista de Iniciação à Docência, v.6, n.2, 2021- \\ Publicação: dezembro, 2021 - ISSN 2525-4332}

que outros por conta da própria natureza do contexto de desenvolvimento da atividade. A exibição do documentário proporcionou as pessoas licenciandas o levantamento preliminar da realidade de Dona Suzana, enquanto que a escolha das contradições, os diálogos descodificadores (feitos de forma limitada a "equipe de educadores" e a construção de problematizações) e a redução temática, materializada na escrita da carta em busca do UTS em questão, foram desencadeadas pelas discussões em grupo. Por fim, a própria produção das cartas se caracteriza como uma situação pedagógica, além de assumir uma tentativa de síntese cultural e de comunicação problematizadora.

Tabela 1: Aproximações verificadas entre a ATF e a atividade proposta.

\begin{tabular}{|l|l|}
\hline \multicolumn{1}{|c|}{ Etapas da ATF (Delizoicov et al., 2018) } & \multicolumn{1}{c|}{ Possíveis aproximações na atividade } \\
\hline i) Levantamento preliminar & Assistir o documentário; fazer anotações. \\
\hline ii) Codificações & $\begin{array}{l}\text { Análises das anotações individuais e discussões em } \\
\text { grupo. }\end{array}$ \\
\hline iii) Descodificação & Discussões em grupos. \\
& $\begin{array}{l}\text { Redação das cartas - Elaboração de problemas e } \\
\text { problematizações em algumas cartas. }\end{array}$ \\
\hline iv) Redução Temática & $\begin{array}{l}\text { Redação das cartas; explicitação de conteúdos } \\
\text { referentes as Ciências Naturais. }\end{array}$ \\
\hline v) Desenvolvimento em sala de aula & $\begin{array}{l}\text { Redação das cartas - assume papel comunicativo } \\
\text { problematizador e dialógico. }\end{array}$ \\
\hline
\end{tabular}

É importante ressaltar que apesar de assumirmos aproximações entre as etapas da ATF com os diferentes momentos da atividade, tendo realizado, de certo modo, uma escuta as problemáticas trazidas por Dona Suzana ao assistirmos com cuidado o referido episódio, afirmamos as limitações desse exercício quanto a seleção das falas significativas. Alinhamos aqui a atividade e o nosso "modo de caminhar" a um objetivo formativo menos amplo que a IT e ATF, nos limitando à sensibilização de estudantes de licenciatura em um momento específico das disciplinas.

Pela própria natureza da atividade e condições em que o trabalho foi desenvolvido, optamos por trabalhar com o contexto de modo geral; nos atendo as temáticas percebidas pelas pessoas licenciandas durante o levantamento preliminar. Outros autores (NERES; GEHLEN, 2018) reconhecem que a ausência de algumas das etapas da IT ou ATF nos estudos podem afetar a autenticidade do processo. No entanto, como diz Solino et al. (2021, p. 24), cabe as pesquisas que vêm sendo desenvolvidas "explicitarem os parâmetros utilizados no processo de análise das falas dos sujeitos, para que se possa compreender como a equipe de pesquisadores realiza a escuta sensível do Outro nas etapas da Investigação Temática". 


\section{-Revista de Iniciação à Docência, v.6, n.2, 2021- \\ Publicação: dezembro, 2021 - ISSN 2525-4332}

Durante a reflexão do exercício de IT proposto e no mecanismo de análise e avaliação das cartas, discriminado no próximo item, pudemos observar, a partir de categorias freireanas, como as pessoas educandas trabalharam nas cartas os aspectos teóricos das disciplinas, especialmente quanto às questões de ciência e tecnologia em relação com a sociedade.

\section{Mecanismo de análise e avaliação das cartas}

Apresentamos este relato com a incorporação de um processo avaliativo da atividade, nos valendo de elementos investigativos dentro dos pressupostos da pesquisa qualitativa que tem como objetivo, a partir de um corpo de dados homogêneos provenientes de atividade didático-pedagógica (cartas), identificar, classificar e sistematizar pela inferência de categorias analíticas e interpretar à luz de nosso arcabouço teórico. Como instrumento metodológico nos baseamos na análise de conteúdo proposta por Bardin (2011).

Como já referido, as unidades de conteúdo aqui apresentadas representam trechos das cartas produzidas por pessoas licenciandas em Pedagogia e Ciências Biológicas. Assim, foram nomeados como: $C$ - carta e número referente a identificação numérica da carta, Pdg - Pedagogia ou Bio - Biologia. Exemplo: C1 - Pdg e C1 - Bio. Deste modo, a partir da leitura das cartas produzidas pelas pessoas licenciandas, identificamos unidades de conteúdos pertinentes às categorias oriundas do pensamento de Paulo Freire que indicam o potencial da atividade proposta: temas ${ }^{5}$, problematização, dialogicidade, síntese cultural e incorporamos em nossas análises a categoria práxis (Tabela 2), pois em algumas cartas a proposição de intervenções sobre a realidade a partir das categorias anteriores pode ser considerado um fator importante.

Tabela 2: Categorias de análise das cartas

\begin{tabular}{|l|l|}
\hline \multicolumn{1}{|c|}{ Categorias } & \multicolumn{1}{c|}{ O que abrange } \\
\hline Temas & $\begin{array}{l}\text { Os temas e conteúdos estão inseridos no UTS. Os conteúdos emergentes são } \\
\text { considerados como produtos de um processo similar ao de codificação e redução } \\
\text { temática proposto inicialmente por Freire (2018). Aqui são apresentados e } \\
\text { expostos na carta a partir de um olhar atento e de busca ativa por questões das } \\
\text { ciências naturais potencialmente presentes no documentário. }\end{array}$ \\
\hline Problematização & $\begin{array}{l}\text { Como os problemas foram construídos e sintetizados nas cartas: há uma conexão } \\
\text { com a realidade apresentada no documentário ou centram-se apenas no conteúdo }\end{array}$ \\
\hline
\end{tabular}

\footnotetext{
5 Optamos pela utilização de "temas" para que não se confunda com a ideia de Temas Geradores apresentada por Freire (2018) e sistematicamente trabalhada por autores que investigam sua inserção no ensino de ciências. Apesar desta atividade estar inspirada no processo pelo qual se obtém Temas Geradores, por compromisso teórico e metodológico com as ideias basilares, nos restringimos a denominação por tema.
} 


\begin{tabular}{|l|l|}
\hline Dialogicidade & $\begin{array}{l}\text { Trentífico e tecnológico emergente? } \\
\text { entre diferentes saberes e cotidianos. Aqui, compreendemos que apenas alguns } \\
\text { aspectos da dialogicidade podem estar presentes devido a natureza da atividade e } \\
\text { o contexto em que se dá. }\end{array}$ \\
\hline Síntese cultural & $\begin{array}{l}\text { Tendo como pressuposto a dialogicidade, essa categoria abrange à incorporação } \\
\text { da perspectiva de síntese cultural (Freire, 2018) como parte da ação dialógica para } \\
\text { a elaboração das cartas por parte das pessoas educandas. }\end{array}$ \\
\hline Práxis & $\begin{array}{l}\text { Proposição de articulações entre os aspectos teórico-conceituais apresentados e } \\
\text { possibilidade de ação, reflexão e intervenção na realidade. }\end{array}$ \\
\hline
\end{tabular}

Para a apresentação de trechos das cartas, seguimos determinações do CONEP apresentadas na resolução 510/2016 em seu artigo $1^{\circ}$ inciso VII "pesquisa que objetiva o aprofundamento teórico de situações que emergem espontânea e contingencialmente na prática profissional, desde que não revelem dados que possam identificar o sujeito" (BRASIL, 2016, p.2). Desta forma, não houve a priori, intencionalidade de pesquisa na proposição da atividade e a análise aqui apresentada configura-se um produto das reflexões sobre a prática profissional das pessoas docentes formadoras.

\section{Cartas sobre um Universo Temático Significativo}

Para Freire (2018) a educação como prática de liberdade, problematizadora e dialógica, tem início pela investigação do universo temático. A atividade proposta teve como principal resultado um exercício, inspirado em proposições da IT e ATF, de sensibilização de pessoas licenciandas para a busca pelo UTS de uma realidade cultural e social, tendo como plano mediador o episódio de Salvador da série documental Street Food América Latina. Neste percurso foram produzidas dezoito cartas no contexto das duas disciplinas de metodologia do ensino aqui apresentadas.

Freire (2018) coloca que a tarefa da pessoa educadora dialógica é retornar, na forma de codificações e problematizações, o UTS com as pessoas que o constituem e o fazem histórico e culturalmente. Assim, as cartas tomaram forma de um exercício de dialogicidade e problematização a partir da compreensão por parte das pessoas licenciandas da existência, e portanto, de sua complexidade, de um universo temático que está imerso na realidade representada no documentário.

Podemos observar enquanto temas ressurgentes, pertencentes a um UTS relacionado às ciências naturais e suas interconexões sociais e culturais, levantado pelas pessoas licenciandas, a alimentação e ganho energético, questões socioambientais e 
culturais referentes às relações com o mar, a introdução de espécies como o dendezeiro, a biodiversidade representada nos ingredientes. Alguns exemplos:

"Achamos muito interessante e vimos vários assuntos que estudamos dentro do curso de biologia, como nutrição, os diferentes tipos de peixes e a extração de óleos vegetais, como o azeite de dendê! Tantas coisas apareceram na sua fala e na sua história de vida que lembram o que a gente estuda, e que nos inspiraram a escrever essa carta." [C11 - bio]

Também, em algumas cartas é possível observar composições que nos aproximam da concepção de redução temática enquanto “operação de ‘cisão' dos temas como parte de totalidades. Dessa forma, reduzir um tema é cindi-lo em suas partes para, voltando-se a ele como totalidade, melhor conhecê-lo" (FREIRE, 2018, p. 116). Os dois trechos seguintes podem elucidar nossa análise:

"Poderíamos partir de coisas simples como a exploração dos ingredientes (de onde eles vêm, como eles chegam até nós) traçando um caminho desde a matéria-prima para a criação do prato, até a finalização pelas mãos da senhora". [C4 - pdg]

"Nós não temos muito contato com a culinária baiana, mas vimos que o seu Antônio traz belos guaricemas para a senhora preparar. Pensando nisso, nós achamos que seria interessante compartilhar com vocês um pouco do que descobrimos sobre os aspectos biológicos desse peixe, apesar de termos certeza de que a senhora e o seu Antônio já conhecem muito sobre ele, principalmente, sobre como pescá-lo e prepará-lo.

Nessas águas profundas, eles costumam ser maiores do que aqueles encontrados nas águas rasas e podem chegar a mais de 1 metro de comprimento e ultrapassar $25 \mathrm{~kg}$. Imagina quanta moqueca não daria para fazer com um peixão desse tamanho, não é mesmo?

Já houve relatos de envenenamento pelo consumo dos guaricemas. Isso acontece quando estes peixes consomem pequenos organismos chamados dinoflagelados, que produzem um veneno que pode afetar nosso sistema nervoso, o coração e o estômago também. Mas não se preocupem! Estes casos são bastante raros, ainda mais no Brasil, já que esses dinoflagelados normalmente não ocorrem por aqui". [C8, bio]

Nos dois trechos apresentados acima observamos de duas formas distintas como os temas e suas "cisão" em conteúdos podem aparecer. No primeiro observamos uma proposta de caminho que direciona como o tema poderia ser reduzido, já no segundo observamos a apresentação de vários conteúdos e assuntos já demarcados. Entretanto, não foi apenas o aparecimento de temas e a redução em conteúdos que nos chamou a atenção ao analisar e avaliar as cartas, foi possível encontrar outros elementos fundamentais do pensamento de Paulo Freire que integram a investigação e abordagem temática: problematização, dialogicidade, síntese cultural e práxis. 


\section{Problematização}

Nas cartas foram observadas problematizações construídas a partir de um olhar cuidadoso para o documentário. Aqui, frisamos que o retorno das codificações enquanto problematizações podem estruturar o momento de decodificação da própria investigação temática, como foi apresentado no item anterior. Freire (2018, p. 64) coloca que "no processo de busca da temática significativa, já deve estar presente a preocupação pela problematização dos próprios temas". Caraterística que pudemos observar na composição das cartas:

"Você já teve problemas por não conseguir algum peixe? Ou algum alimento específico? Já encontrou plástico ou outro material em algum peixe? Pois é, isso nos fez pensar sobre a questão das mudanças climáticas que vêm ocorrendo no nosso planeta em decorrência das atividades industriais, em especial das

grandes potências mundiais, cujo modelo econômico vem afetando o nosso planeta, não diferente, os oceanos e rios. Dona Suzana, a forma como todas as pessoas tratam o planeta reflete na nossa sobrevivência. Com o mar, então, nem se fala! Se é por ele que a senhora tem grande apreço, é nele também que mais ocorrem problemas que precisam ser revertidos o mais rápido possível." [ $\mathrm{C}_{3}$ - pdg]

O trecho posto, também nos aproxima ao que Delizoicov (2005) formula em sua discussão sobre problemas e problematizações. Podemos perceber a inserção de problemas oriundos de um universo temático que passa a ser problematizado pelas pessoas licenciandas. Abaixo, apesar de apresentar algumas informações, notamos em diferentes trechos de uma carta problemas postos para provocar reflexões que podem mobilizar o processo de problematização.

"A partir de suas palavras, conseguimos sentir a importância que a praia, o mar e a pesca têm para você e seu marido, Antônio. Não pudemos deixar de notar a presença de grandes navios durante algumas cenas que mostravam seu marido pescando. Sabemos do grande impacto que eles causam na vida marinha e nas comunidades pesqueiras ali da região. Por exemplo, menor número de peixes quando há muitos navios ou diferenças no sabor da carne do peixe, devido a poluição. Gostaríamos de saber se a senhora e o seu marido sentem este impacto.

Também pesquisamos sobre o Porto de Salvador e vimos algumas das medidas que são tomadas para garantir o funcionamento desse porto, como a dragagem. Durante esse processo muita areia é suspensa na água do mar e isso, assim como os navios, pode levar à diminuição dos peixes. Vocês já repararam neste efeito durante a pesca?

No caso de vocês sentirem estes impactos negativos da presença do porto e do aumento do fluxo de navios na região, gostaríamos de entender como vocês lidam com esses prejuízos. O governo fornece algum auxílio?" [C14 - bio]

Este trecho nos aproxima dos ideais da educação problematizadora, reflexiva e comprometida com o desvelamento da realidade. Para Freire (2018) enquanto a educação bancária pretende a "imersão", a educação problematizadora tem como 
-Revista de Iniciação à Docência, v.6, n.2, 2021-

Publicação: dezembro, 2021 - ISSN 2525-4332

objetivo a "emersão" de consciências que se desdobram sobre a realidade. Por isto, a problematização é um convite ao desafio:

"Tão mais desafiados, quanto mais obrigados a responder ao desafio. Desafiados, compreendem o desafio na própria ação de captá-lo. Mas, precisamente porque captam o desafio como um problema em suas conexões com outros, num plano de totalidade e não como algo petrificado, a compreensão resultante tende a tornar-se crescentemente crítica, por isto, cada vez mais desalienada". (FREIRE, 2018, p. 45).

Entretanto, a problematização dentro de uma perspectiva Freireana é o ponto de partida e chegada da ação dialógica. Será que é possível estimular a produção de cartas dialógicas a partir da atividade aqui proposta?

\section{Dialogicidade}

A educação em Freire é dialógica-problematizadora. Observamos que a atividade proposta pode ser um exercício de problematização. Mas seria possível fomentar a construção de processos de dialogicidade na formação inicial de professores? Entre tantas argumentações sobre a dialogicidade, Freire (2018) coloca que o diálogo é:

\footnotetext{
"o encontro dos homens para a tarefa comum de saber agir, se rompe, se seus polos (ou um deles) perdem a humildade. Como posso dialogar, se alieno a ignorância, isto é, se a vejo sempre no outro, nunca em mim? Como posso dialogar, se me admito como um homem diferente, virtuoso por herança, diante dos outros, meros "isto", em quem não reconheço outros eu?" (FREIRE, 2018, p.51).
}

Delizoicov et al. (2018) pontuam que o diálogo é uma ação que leva em conta significados e interpretações de pessoas educandas em conjunto com os conhecimentos da pessoa educadora. Ou seja, o diálogo é posto na sinergia de saberes no qual "ambos os sujeitos da educação, aluno e professor, detém a respeito do tema, objeto de estudo e compreensão" (DELIZOICOV et al., 2018 p. 149).

Com compromisso teórico, destacamos que aqui falamos de alguns aspectos da dialogicidade como a escuta e compreensão da realidade por parte das pessoas professoras e educadoras em formação, bem como o estímulo para o desenvolvimento da amorosidade fortemente pautada em Freire. A dialogicidade é fundamental para a educação como situação gnosiológica, na qual a autêntica comunicação entre duas partes em torno de um objeto comum se faz necessária (FREIRE, 1985) e naturalmente exige dois polos em interação, escuta, debates, trocas, construções etc. Entretanto, é importante notar que o modelo de documentário participativo permite com que vozes 
sejam ouvidas e protagonizadas, como a de Dona Suzana. Mesmo que sem contato físico, ou referência direta a boa parte dos temas levantados pelas pessoas licenciandas, é de se saber que sua voz é central e constituinte daquele UTS. Assim, inferimos que nesta atividade, a dialogicidade surge principalmente no cuidado na composição da comunicação nas cartas:

"A ciência que tenho certeza de que a senhora conhece. A ciência da natureza, a sua ciência, mexida por suas mãos, através do dendê, do sururu, do tempero da moquequinha no ponto certo". [ $C_{1}$ pdg]

"Mas, assistindo sua história podemos perceber que sua relação com o mar é muito mais profunda e bonita. Ela vai muito além de saber o nome dos animais. É uma relação de espiritualidade, de afetividade, $e$ sobretudo de sobrevivência. O seu conhecimento sobre o mar é tão importante quanto o nosso, você vive do lado dele há tantos anos que com certeza sabe de coisas que nenhum cientista no mundo sabe sobre ele. Mas uma coisa tenho certeza que nós temos em comum: sabemos o quanto é importante cuidarmos dessa imensidão azul. Quando estudamos formas para que os seres vivos do oceano continuem a existir, estamos pensando também numa forma para que o nosso amor por ele possa ser compartilhado, assim como a sua comida, onde você compartilha um pouco do seu amor com aqueles que a experimentam" [C10 - bio]

Ao fundar-se no amor, na humildade, na fé nos homens, o diálogo se faz uma relação horizontal, em que a confiança em um polo no outro e consequência óbvia. Seria uma contradição se, amoroso, humilde e cheio de fé, o diálogo não provocasse este clima de confiança entre os sujeitos. Por isto inexiste esta confiança na antidialogicidade da concepção bancária da educação. (FREIRE, 2018, p. 113).

O cuidado apresentado pelos licenciandos é uma forma de aproximação e receptividade para propor um diálogo e problematização sobre o mundo junto à Dona Suzana. Para Freire (1985) é no movimento dialógico que as pessoas educadoras e educandas desenvolvem juntas uma postura crítica, na interação que ambas poderão refletir e transformar o mundo. Notamos que aspectos da premissa dialógica esteve presente nesta atividade, a seguir veremos como o diálogo expande-se na convergência de mundos, de visões integradoras que constituem a síntese cultural.

\section{Síntese Cultural}

Para Freire (2018) a investigação de temáticas significativas que tem por objetivo a "captação" de temas básicos presentes no cotidiano de pessoas em suas realidades só é possível pela ação da síntese cultural. Sob este prisma, Oliveira \& Linsingen (2019) apropriam-se da perspectiva decolonial que valoriza outras formas de conhecimento na educação em ciências que inclui a crítica à visão de ciência moderna hegemônica. Assim, argumentam a necessidade de uma educação CTS latinoamericana que rompa com visões universalizadas e hierarquizantes (sexismo, gênero, determinismo biológico, escrita/oralidade e ocidente/oriente) que são características dos processos de dominação 
e invasão cultural. Destacamos a existência de um viés multicultural e decolonial na construção de algumas cartas:

"Nos toca, sobretudo, a forma como você preserva e aplica no cotidiano e com muita naturalidade uma sabedoria tradicional que, ao analisarmos, percebemos como sendo composta de conhecimentos legitimamente históricos e científicos. As práticas culinárias que você preserva em um mundo que tende cada vez mais à massificação industrial são parte de um patrimônio cultural valioso, um modo de viver e de fazer as coisas que sobrevive pela força de pessoas extraordinárias, e que não é menos sofisticado ou técnico por não receber todo o prestígio que se costuma dar à culinária que atende as classes mais abastadas de nossa sociedade."[C2 - pdg]

"Nos chamou atenção as fortes raízes africanas da cultura baiana, que podemos ver nas danças, ritos $e$ também na culinária, como o azeite de dendê, usado na comida que a senhora faz. Aprendemos no documentário que esse azeite vem do fruto de uma palmeira trazida da África pelos escravos, a palmeira africana ou dendezeiro. É incrível o quanto a natureza está presente na nossa vida, conectando África e Bahia, moqueca de dendê, comida e pessoas. Por isso precisamos cuidar do meio ambiente e da nossa cultura." [C12 - bio]

Segundo Freire (2018), a síntese cultural é o oposto da invasão cultural, que por sua vez objetiva sobrepor uma cultura sobre a outra com o intuito de conquistar as massas, submetendo-as a uma constante alienação. Nesse sentido, a síntese cultural, aqui entendida como uma ação cultural dialógica, visa superar as contradições que dificultam a libertação do ser humano. Freire (2018) também aponta que a ação da invasão cultural dos atores é mediatizada cada vez mais por instrumentos tecnológicos, impondo aos homens do povo seus objetos e ideologias dominantes:

\footnotetext{
"A síntese cultural pretende a integração dos homens do povo e sua ação no mundo e se apresenta como instrumento de superação da cultura alienante. Nesse sentido, a investigação dos temas geradores tem como objetivo organizar o conteúdo programático que se instaura como ponto de partida do processo da ação libertadora, do restabelecimento do clima de criatividade, do fortalecimento da análise crítica. Estes aspectos são essenciais para que ocorra a síntese cultural”. (PEREIRA, 2018).
}

Decerto, é de se esperar que na síntese cultural os atores se integrem com os homens do povo, aqui também assumidos como atores, em uma ação significativa sobre o seu respectivo mundo. Mesmo sem ter ocorrido, de fato, uma imersão presencial à realidade de Dona Suzana, o exercício de síntese cultural proposto pôde ser experienciado pelas pessoas licenciandas, uma vez que houve a tentativa, na produção das cartas, de realizar uma ação cultural dialógica entre os mundos dos atores em questão. 
A práxis em Freire (2018) é a relação dialética entre pensamento, consciência e a intervenção transformadora na realidade. É, portanto, uma atribuição subjetiva mas também coletiva, pois se dá na ação dialógica entre pessoas educadoras e educandas, entre partícipes do e com o mundo. Aqui, nossa interpretação mostra que o reconhecer problematizador, o diálogo sobre a realidade de Dona Suzana e a síntese de um universo temático multicultural são elementos fundamentais para que humildemente fossem desenhados pelas pessoas licenciandas universos temáticos. Neste processo, em sintonia com as ciências naturais, podemos observar que algumas cartas trouxeram, para além da reflexão, convites para a ação a partir de contradições visíveis ou não no documentário.

"Nós sabemos que temos grande responsabilidade sobre a forma como agimos e tratamos a mãe Terra, mas também precisamos entender e pressionar os maiores produtores de plástico e produtos não recicláveis, bem como cobrar nossos governantes para que deliberem leis mais rígidas de proteção das florestas, dos animais e diminuição de poluentes, não acha? Com nossas pequenas mudanças de comportamento e as grandes mudanças das corporações e governantes, talvez possamos pensar num futuro mais diverso, sustentável e melhor, não é mesmo? Grande parte da beleza de Salvador e do nosso Brasilzão vem da natureza, e nada melhor do que lutarmos para que ela permaneça linda e viva!" [C3 - pdg]

"Seu trabalho é muito delicado e exige bastante cuidado, desde a pesca até o produto final na cozinha. Acreditamos que seria interessante para a senhora, de alguma forma, entrar em contato com ONGs ambientalistas que possam te informar como a senhora mesma pode perceber quando houver algo de errado no mar que dá pra ver da janela da sua casa, como sinais de poluição ou contaminação, despejo irregular de substâncias, entre outros, e assim avisar para elas esses ocorridos. Desse modo, a senhora terá mais confiança e poderá contribuir cuidando não só da qualidade do produto que usa no restaurante, mas também cuidará do lugar onde vive e de todos os animais e plantas que também vivem no mar, preservando um dos amores da sua vida." [C7 - bio]

O estímulo à reflexão e à ação rumo a mobilização em seu contexto presente nos trechos acima nos aproximam ao que Freire (1981) formula enquanto uma atitude comprometida e não neutra perante a realidade a ser conhecida, problematizada e modificada. Este processo só se dá na ação e na reflexão.

Kauano (2019), a partir de reflexões marxistas e freireanas da práxis, argumenta que processos de aprendizagem de conceitos científicos junto a mobilização de outros conteúdos e saberes são estruturantes para ações conscientes sobre uma determinada realidade. Aqui, tomamos a práxis enquanto algo a se buscar, incentivada pelas palavras de pessoas licenciandas nas palavras que compõem as cartas. Com esta postura nos aproximamos dos postulados de Freire (2013) sobre a busca pela unidade de ação e reflexão que "não é uma coisa que se deposita nos homens. Não é uma palavra oca, 


\section{-Revista de Iniciação à Docência, v.6, n.2, 2021- \\ Publicação: dezembro, 2021 - ISSN 2525-4332}

mitificante. É práxis, que implica a ação e reflexão dos homens sobre o mundo para transformá-lo" (FREIRE, 2013, p.93).

\section{Considerações Finais}

Assim como indica Freire (2018), escolhemos um "modo de caminhar" para este exercício de IT diante das limitações impostas pela pandemia do coronavírus. É importante ressaltar que a atividade foi desenvolvida em um contexto de ensino remoto, visto que durante o período em que a disciplina foi oferecida não foi possível realizar encontros e ações presenciais. Por isso, vale frisar que esta atividade, embora tenha se ancorado em pressupostos freireanos, trata-se de um exercício que tem como base inspiradora a IT e a ATF e que pode ser utilizado/modificado em outros contextos de formação de pessoas educadoras. Também, para além de potencialidades, em compromisso com o reconhecimento de limitações, ressaltamos que o processo metodológico que nos inspira, em prática, mantém diferenças substanciais que devem ser consideradas pelas pessoas que leem este trabalho.

Prosseguindo em nossas considerações, destacamos que podemos distinguir claramente dois momentos da atividade que foram aqui apresentados: i) o processo inspirado em IT, representado pelo planejamento e execução da atividade; e ii) o produto do processo, que embora tenha suas semelhanças com a etapa de redução temática e situação de ensino, traz em si elementos importantes quando observados pelas categorias presentes na obra de Freire.

Retomamos neste momento a pergunta que levantamos em nossa introdução: "Documentários que relatam e exploram determinadas realidades poderiam mediar e auxiliar pessoas educadoras em formação inicial a começar a desenvolver olhares atentos para a percepção de contradições e alguns aspectos estruturantes de contextos de vida que são fundamentais à IT?". O exercício aqui apresentado, embora não mobilize em sua integralidade o que entende-se classicamente por IT, foi capaz de mobilizar aspectos centrais da teoria educacional de Paulo Freire expressos no fundamento codificaçãoproblematização-descodificação da IT classicamente postulada (FREIRE, 2018). Podemos, após esta cuidadosa avaliação transformada neste relato, considerar a grande potencialidade no uso de documentários participativos ${ }^{6}$ para exercícios de apreensão e sensibilização de universos temáticos significativos.

Não podemos deixar de citar a riqueza da história de Dona Suzana, em soma com todos os elementos socioculturais apresentados, certamente fatores que tornaram esta atividade tão positiva. Ao considerar desta riqueza de informações presentes no documentário, conseguimos a partir desses pressupostos teóricos mobilizar o olhar de

\footnotetext{
${ }^{6}$ Deixamos como indicação outro documentário que pode se trabalhado em contextos problematizadores de formação de pessoas educadoras em ciências: o documentário "Carta para além dos muros" retrata a história da epidemia de HIV/Aids no Brasil trazendo múltiplas vozes partícipes de processos sociais e científicos deste episódio, ainda não findado, de nossa história.
} 


\section{-Revista de Iniciação à Docência, v.6, n.2, 2021- \\ Publicação: dezembro, 2021 - ISSN 2525-4332}

discentes para a existência de um UTS composto de uma diversidade de temas implícitos ou explícitos, fugindo das visões tradicionais hegemônicas na práxis educativa que coloca os conceitos das ciências da natureza enquanto início e fim da atividade. Sendo assim, em consonância com Delizoicov et al. (2018), alcançamos um dos objetivos da atividade que é colocar temas antes de conceitos quando discutimos questões de ciência e tecnologia seja na formulação de programas escolares, ou no nosso caso, na construção de um exercício de produção de uma carta dialógica e problematizadora.

Notamos que para além da percepção de um UTS, há incorporação de elementos presentes nas categorias de Paulo Freire na composição das cartas, sendo que a problematização, dialogicidade, síntese cultural e práxis foram elementos marcantes. Este fato, sistematicamente apresentado ao longo deste trabalho, nos permite uma avaliação extremamente positiva desta atividade dada a riqueza, delicadeza e amorosidade percebidas nas cartas. Para além de pressupostos teóricos e metodológicos, consideramos que o que esteve em jogo foi a humanização, elemento de nossa construção histórica e cultural tão apagado ao longo dos séculos de dominação cultural. Este aspecto, também nos coloca em sinergia com importantes debates a respeito dos caminhos atuais da educação em ciências que vêm ressaltando a importância da formação humanística de pessoas professoras e educadoras, sensíveis às complexas realidades e aos objetivos e valores da profissão. Tudo isto, em contramão a projetos e políticas públicas como a BNC-Formação que traz em si uma proposta de mecanização e pormenorização da formação inicial e continuada de professores (RODRIGUES et al., 2020).

Ao reconhecer, compreender e reconstituir o UTS, a pessoa educadora também mergulha em um processo formativo, de aprender com e no mundo. Aqui falamos de um exercício para novas consciências educadoras que encontram no chão da vida partilhada os subsídios para a práxis educativa libertadora e problematizadora. Assim, não poderíamos deixar de encerrar com as palavras de Freire (1981, p. 13) o relato desta valorosa e emocionante experiência de formação de pessoas educandas-educadoras: "os textos, as palavras, as letras daquele contexto se encarnavam também no assobio do vento, nas nuvens do céu, nas suas cores, nos seus movimentos; na cor das folhagens, na forma das folhas, no cheiro das flores [...] no corpo das árvores, na casca dos frutos".

\section{Referências}

ANGOTTI, José André Peres; AUTH, Milton Antonio. Ciência e tecnologia: implicações sociais e o papel da educação. Ciência \& Educação, Bauru, v. 7, n. 1, p. 15-27, 2001.

Disponível em: <https://www.scielo.br/j/ciedu/a/cpQBQWf3L6SQWqnffgM4NrF/?lang=pt\&format=pdf>. Acesso em: 19 jul. 2021.

AULER, Décio. Alfabetização Científico-Tecnológica: Um novo “paradigma”? Ensaio Pesquisa em Educação em Ciências v. 05, n. 01, p. 69-83, 2003. Disponível em: 
<https://www.scielo.br/j/epec/a/jp44NGpsBjLPrhgMz6PttHq/?format=pdf\&lang=pt>. Acesso em 19 jul. 2021.

AULER, Décio; DELIZOICOV, Demétrio. Investigação de temas CTS no contexto do pensamento latino-americano. Linhas Críticas, [S. I.], v. 21, n. 45, p. 275-296, 2015. DOI: 10.26512/lc.v21i45.4525. Disponível em:

<https://periodicos.unb.br/index.php/linhascriticas/article/view/4525> Acesso em: 4/out/ 2021.

AULER, Décio; DELIZOICOV, Demétrio. Alfabetização científico-tecnológica para quê?.

Ensaio - Pesquisa em Educação em Ciências. v. 03, n. 2, p. 122-134, 2001. Disponível em:<https://www.scielo.br/j/epec/a/XvnmrWLgL4qqN9SzHjNq7Db/:lang=pt\&format=pdf > Acesso em 27 jul. 2021.

BARBOSA, Leila Cristina Aoyama; BAZZO, Walter Antonio. O Uso De Documentários Para O Debate Ciência-Tecnologia-Sociedade (Cts) Em Sala De Aula. Ensaio - Pesquisa Em Educação Em Ciências, v. 15, n. 3, p. 149-161, 2013. Disponível em: <https://www.scielo.br/j/epec/a/qTTHWYt6dpYwrfgVpJ63myp/?lang=pt>. Acesso em: 12 jul. 2021.

BARDIN, Laurence. Análise de conteúdo. SP: Edições 70, 2011.

BRASIL. Ministério da Saúde. Conselho Nacional de Saúde. Resolução 510/2016: ética em pesquisa em Ciências Humanas e Sociais. Brasília: Ministério da Saúde, 07 abr. 2016. Disponível em: <http://conselho.saude.gov.br/resolucoes/2016/Res0510.pdf $>$.Acesso em 03 ago. 2021.

CENTA, Fernanda Gall; MUENCHEN, Cristiane. O trabalho coletivo e interdisciplinar em uma reorientação curricular na perspectiva da Abordagem Temática Freireana. Revista Eletrónica de Enseñanza de las Ciencias. v. 17, n. 1, p. 68-93, 2018. Disponível em: $<$ http://reec.uvigo.es/volumenes/volumen17/REEC 17_1_4_ex1115.pdf >. Acesso em 30 jul. 2021.

DELIZOICOV, Demétrio. Concepção problematizadora do ensino de ciências na educação formal: relato e análise de uma prática educacional na Guiné Bissau. 1982. $227 \mathrm{f}$. Dissertação (Mestrado) - Universidade de São Paulo, São Paulo, 1982.

DELIZOICOV, Demétrio. O ensino de física e a concepção freireana da educação. Revista de Ensino de Física. São Paulo, v. 5, n. 2, 1983.

DELIZOICOV, Demétrio. Problemas e problematizações. In: PIETROCOLA, M. (Org.). Ensino de Física: conteúdo, metodologia e epistemologia em uma concepção integradora. Florianópolis: UFSC, p. 125-150, 2005.

DELIZOICOV, Demétrio; ANGOTTI, José André; PERNAMBUCO, Marta Maria Castanho Almeida. Ensino de ciências: fundamentos e métodos. São Paulo: Cortez, 2018.

DEMARTINI, Gabriel. Ribeiro.; SILVA, Antonnio. Fernando. Gouvêa. da. Abordagem Temática Freireana no Ensino de Ciências e Biologia: Reflexões a partir da Práxis Autêntica. Revista Brasileira de Pesquisa em Educação em Ciências, [S. I.], p. e33743, 1-, 
-Revista de Iniciação à Docência, v.6, n.2, 2021-

Publicação: dezembro, 2021 - ISSN 2525-4332

2021. DOI: 10.28976/1984-2686rbpec2021u9731002. Disponível em:

https://periodicos.ufmg.br/index.php/rbpec/article/view/33743. Acesso em: 1 out. 2021.

FREIRE, Paulo. Ação cultural para a liberdade. 5 ed, Rio de Janeiro, Paz e Terra, 1981

FREIRE, Paulo. Extensão ou comunicação?. Editora Paz e Terra, 1985.

FREIRE, Paulo. Pedagogia da Autonomia. 45 ed, Rio de Janeiro, Paz e Terra, 2013.

FREIRE, Paulo. Investigação e metodologia da investigação do tema gerador. In: TORRES, Carlos Alberto. Diálogo e práxis educativa: uma leitura crítica de Paulo Freire. São Paulo: Edições Loyola, p. 95-107, 2014.

FREIRE, Paulo. Pedagogia do oprimido. Rio de Janeiro: Paz e Terra, 2018.

GEHLEN, Simoni Tormöhlen. A função do Problema no Processo Ensino-Aprendizagem de Ciências: Contribuições de Freire e Vygotsky. 2009. Tese de Doutorado. Programa de Pós-Graduação Educação Científica e Tecnológica da Universidade Federal de Santa Catarina, Florianópolis. 2009.

GEHLEN, Simoni Tormöhlen, Strieder, R. B., Caramello, G. W., Feistel, R. A. B., \& Halmenschlager, K. R. A inserção da abordagem temática em cursos de licenciatura em Física em instituições de ensino superior. Investigações em Ensino de Ciências, 19(1), 155175. 2014 .

JESUS, Rosane Meira Vieira. Escola e documentário: uma relação antiga. Revista HISTEDBR On-line, Campinas, n.32, p.233-242, 2008. Disponível em: <https://feold.fe.unicamp.br/pf-fe/publicacao/5103/art17_32.pdf>. Acesso em: 30 jul. 2021.

KAUANO, Rafael Vitame. Catar coral-sol: as potencialidades do manejo de espécies invasoras enquanto promotor de processos de aprendizagem situada e práxis. 2019. 158 f. Tese (Doutorado em Ensino de Biologia) - Ensino de Ciências (Física, Química e Biologia), Universidade de São Paulo, São Paulo, 2019.

MUENCHEN, Cristiane, AULER, Décio. Abordagem temática: desafios na educação de jovens e adultos. Revista Brasileira de Pesquisa em Educação em Ciências, 7(3), 1-17. 2007.

MUENCHEN, Cristiane. A disseminação dos três momentos pedagógicos: um estudo sobre práticas docentes na região de Santa Maria/RS. 2010. Tese de Doutorado. Programa de Pós-Graduação em Educação Científica e Tecnológica da Universidade Federal de Santa Catarina, Florianópolis. 2010.

NASCIMENTO, Tatiana Galieta; VON LINSINGEN, Irlan. Articulações entre o enfoque CTS e a pedagogia de Paulo Freire como base para o ensino de ciências. Convergencia, Toluca, v. 13, n. 42, p. 95-116, 2006. Disponível em:

<http://www.scielo.org.mx/scielo.php?script=sci_arttext\&pid=S140514352006000300006\&lng=es\&nrm=iso >. Acesso em: 12 ago 2021.

NICHOLS, Bill. Introdução ao documentário. Campinas, São Paulo: Papirus, 2005. 
NERES, Cleilde Aguiar; GEHLEN, Simoni Tormöhlen. Investigação Temática na Formação de Professores: Indicativos da Pesquisa em Educação em Ciências. Revista Brasileira de Pesquisa em Educação em Ciências, [S. I.], v. 18, n. 1, p. 239-267, 2018. Disponível em: https://doi.org/10.28976/1984-2686rbpec2018181239. Acesso em: 01 out. 2021.

OLIVEIRA, Maíra Caroline Defendi; LINSINGEN, Irlan von. Reflexões acerca da educação CTS Latino-americana a partir das discussões do grupo de pesquisa DICITE da UFSC. In: CASSIANI, Suzani; LINSINGEN, Irlan von. (Orgs.). Resistir, (re)existir e (re)inventar a educação científica e tecnológica. 1ed. Florianópolis: NUP/CED/UFSC, 2019, v. 1, p. 178-193, 2019.

PEREIRA, Elisabete Monteiro de Aguiar. A teoria da Ação Antidialógica. In: Paulo Freire Formação Continuada de Professores: uma ênfase cultural. p. 1-7, 2018.

PERNAMBUCO, Marta Maria Castanho Almeida. Ensino de Ciências a Partir de Problemas da Comunidade. Dissertação (Mestrado) - Instituto de Física, Faculdade de Educação da Universidade de São Paulo, São Paulo, 1981.

PERNAMBUCO, Marta Maria Castanho Almeida. Acertando o passo. In: PONTUSCHKA, Nidia Nacib (Org.). A ousadia do diálogo: interdisciplinaridade na escola. São Paulo: Loyola, 1993.

PERNAMBUCO, Marta Maria Castanho Almeida; MENEZES, Luiz Carlos de. Educação e escola como movimento - do ensino de ciências a transformação da escola pública. 1994. Universidade de São Paulo, São Paulo, 1994.

RODRIGUES, Larissa. Zancan; PEREIRA, Beatriz; MOHR, Adriana. O Documento "Proposta para Base Nacional Comum da Formação de Professores da Educação Básica” (BNCFP): Dez Razões para Temer e Contestar a BNCFP. Revista Brasileira de Pesquisa em Educação em Ciências, [S. I.], v. 20, n. u, p. 1-39, 2020. DOI: 10.28976/1984-2686rbpec2020u139. Disponível em: https://periodicos.ufmg.br/index.php/rbpec/article/view/16205. Acesso em: 1 out. 2021.

ROSA, S. E. da; STRIEDER, R. B. Perspectivas para a Constituição de uma Cultura de Participação em Temas Sociais de Ciência-Tecnologia. Revista Brasileira de Pesquisa em Educação em Ciências, [S. I.], p. e29619, 1-, 2021. DOI: 10.28976/19842686rbpec2021u831857. Disponível em: https://periodicos.ufmg.br/index.php/rbpec/article/view/29619. Acesso em: 1 out. 2021.

SANTOS, Rosemar Ayres dos; AULER, Décio. Práticas educativas CTS: busca de uma participação social para além da avaliação de impactos da Ciência-Tecnologia na Sociedade. Ciência \& Educação (Bauru), v.25, p. 485-503, 2919.

SILVA, Antonio Fernando Gouvêa. A construção do currículo na perspectiva popular crítica: das falas significativas às práticas contextualizadas. 2004. 485 f. Tese (Doutorado em Educação e Currículo). Pontifíca Universidade Católica de São Paulo, São Paulo, 2004.

SILVA, Antonio Fernando Gouvêa (Org.). A busca do tema gerador na práxis da educação popular. Gráfica Popular. 2007. 
SOLINO, Ana Paula; SOUZA, Polliane Santos de; SILVA, Roger Magalhães da; GEHLEN, Simoni Tormöhlen. O Tema Gerador na Formação de Pedagogas do Alto Sertão Alagoano: da Escuta Sensível ao Planejamento de Ciências. Revista Brasileira de Pesquisa em Educação em Ciências, v. 20, p. 1-30, 2021. Disponível em: https://doi.org/10.28976/19842686rbpec2021u10691098. Acesso em: 01 out. 2021.

SOUZA, Polliane Santos; SOLINO, Ana Paula.; FIGUEIREDO, Priscila Silva; GEHLEN, Simoni. Investigação temática no contexto do ensino de ciências: relações entre a Abordagem Temática Freireana e a práxis curricular via tema gerador. Alexandria: Revista de Educação em Ciência e Tecnologia, 2014, v,7 n.2, p. 155-177, 2014.

TORRES, Juliana Rezende. Educação Ambiental Crítico-Transformadora e Abordagem Temática Freireana. 2010. 456 f. Tese (Doutorado em Educação Científica e Tecnológica). Universidade Federal de Santa Catarina, Florianópolis, SC, 2010.

TORRES, Eduardo Cintra. O recurso à ficção em dois filmes documentais portugueses. $p$. 27-37. In: BORGES, Gabriela; PUCCI JR., Renato; SELIGMAN, Flávia (eds.) Televisão:

Formas Audiovisuais de Ficção e de Documentário, Volume I. Faro e São Paulo, 2011. 